\title{
Controlling Marine Fisheries 50 Years from Now
}

\author{
Andrew A. Rosenberg \\ Northeast Regional Administrator, NOAA/National Marine Fisheries Service \\ Gloucester, Massachusetts 01930, USA
}

\begin{abstract}
Fisheries have always been in a state of change, even though it is an activity rooted in long tradition and with a strong culture. Though many fishermen come from fishing families, most do not work as their fathers did either in capture methods, nor target species nor market strategies. In fact, the changes in fishing practices have resulted in the overharvest of many traditional species and international problems of depleted stocks and industry overcapacity.
\end{abstract}

Fishery managers and scientists are constantly changing too and in some cases, the overharvesting problem is beginning to be addressed. In the Northeastern U.S., New England groundfish have been under intense fishing pressure for more than 30 years, but in the past two years, management changes have been enacted which have finally reduced the harvest rate on many groundfish stocks to a level which is already leading to the beginnings of a recovery. This change gives some insight into how the fishery may look in the future. The following features are those that I see emerging out of the current climate: 1) fishing enterprises, large and small, will become generalists rather than specialists; 2) full access control will be implemented for all marine resources and will include addressing the participation of all user groups; 3) with property rights will come responsibility for conservation. The tools for change are new monitoring systems including satellite tracking and increased dockside monitoring, using access as a means of ensuring compliance with conservation measures, and the use of a precautionary approach to management decisions. Though optimistic, given the history of resource management, these changes are both inevitable and can lead to sustainable resource use in the next century.

Keywords: fishing trends, management, precautionary approach

\section{Introduction}

Fisheries have always been in a state of change, in spite of the fact that commercial and recreational fishing have a long tradition and culture passed down from generation to generation. The spirit and ethos of fishing has been maintained while the practice has changed enormously in the last 50 years. There is a familiar pattern to the exploitation of many fisheries repeated in many areas for many stocks, of a fishing up period, followed by a decline due to overharvest and then, in some cases stabilization. That pattern also has occurred for the aggregate of harvested stocks over a broader time scale. As individual stocks were overexploited, the fishery expanded to additional species previously regarded as by-catch, and possibly discarded. Such a pattern is exacerbated by management systems that allow uncontrolled access to the resource. In such a circumstance, open access usually results in a substantial increasing in harvesting capacity, well beyond levels that can be sustained by the resource. Such overcapacity encourages a continuing pattern of risky management decisions, always tending to be less restrictive in the face of uncertainty about the status of the resource or the amount of harvesting pressure it can sustain, because of economic and social pressures. A cycle of overharvesting results until, in the words of the late, great John Gulland, "all doubt is removed and so are the fish" (Sissenwine and Rosenberg, 1994).

There have been some recent, major changes in the fisheries management climate that may lead to a brighter future. In this paper I will briefly review those changes, which have also been covered in several other papers during the symposium in more detail. I will also show how this change in climate is starting to be implemented in the New England groundfish fishery, where the seeds of a stock recovery have been sown. First, however, at the request of the symposium organizers, I would like to speculate on where I 
think fishery management is heading 50 years from now based on these recent changes in the management climate.

In my view, we are in fact moving toward stable use of fish resources with a few key characteristics:

1) A very reduced level of harvesting capacity with a mix of vessel sizes and types of operations. I would speculate that there will continue to be a major role for small-scale harvesting operations (small, owner operator businesses) in future, but overall capacity will be relatively low and open access will be a thing of the past. Property right based systems will be in place for all fisheries, though there will be great variety in the types of systems used (Bromley, 1992; Rosenberg et al., 1993).

2) The industry will be very diversified with a very wide product range and very little discard of unwanted catch.

3) There will be a very high value for fishery products and a demand for higher quality than ever seen before. Profitability will increase at lower capacity, and new product markets will continue to develop such that fisheries will stabilize without the subsidy arrangements so common around the world.

4) There will be a very low tolerance in the industry, general public and the government for violations of the rules. In limited access programs that contain some form of property rights it will not be sensible or feasible to turn a blind eye to those who refuse to cooperate.

5) Most importantly in my view, we will have low maintenance management systems with relatively simple sets of government rules compared to the present situation. The focus on science will be very strong, not to control the harvest, but to maximize efficiency and minimize risk of downturns in production.

If these five predictions are, in fact, the direction fisheries is heading, it will certainly not be without substantial upheaval along the way. Fifty years is a long time in the lifespan of most exploited marine species and fishery dependent businesses, but it is relatively short in terms of system changes which result in a fundamentally different basis for harvesting the sea. After all, open access systems with only indirect controls on harvesting have been in place for a very long time, in spite of decades of evidence that overharvesting can have devastating consequences for resources and fisheries (see Rosenberg et al., 1993 for examples). However, in my opinion, there are few alternatives to a fundamental change in the way we prosecute and manage marine resource use.

\section{The Changing Management Climate}

There are four important changes that have occurred in the last two years; The United Nations agreement on management of straddling and highly migratory stocks (UN, 1995), the FAO Code of Conduct for Responsible Fishing (FAO, 1995a), the inclusion of the concept of a precautionary approach to resource management and, within the United States, new fisheries legislation called the Magnuson-Stevens Fishery Conservation and Management Act (NOAA, 1996). These changes indicate a substantial shift in the philosophy of fishery management and the political will to implement management programs that will not repeat the mistakes of the past. There have been both failures and successes in the history of fishery management, but that the failures have often been the result of a lack of political will to take necessary steps in the face of substantial industry opposition. Rarely have they been the result of technical errors or insufficient scientific information (Rosenberg et al., 1993).

The United Nations Conference on the Management of Straddling Fish Stocks and Highly Migratory Fish Stocks (UN, 1995) was a major advance in setting an international framework for fisheries management. The provisions of the resulting agreement have been extensively discussed in other papers in this symposium. In general, the principles of managing, internationally, for sustainability incorporating ecosystem considerations and strengthening the role of regional fishery organizations in a binding treaty gives a new international framework for fisheries management, though certainly most of the incorporated 
concepts have been part of the management landscape for a long time. What is new is the explicit incorporation in the treaty of the principles of using a precautionary approach to fishery management, setting a new ethic for marine resource use.

The ideas espoused in the agreement are further carried forward and described in detail in the FAO Code of Conduct for Responsible Fisheries (FAO, 1995a). The code clearly spells out that the right to fish carries a conservation obligation with it. The code also specifically notes the problems of overcapacity and recommends preventing the build up of excess fishing capacity as part of any responsible fisheries management program. The issue of habitat protection and by-catch are also addressed in the code with an emphasis on developing appropriate fishing technology to reduce non-target catch. The application of a precautionary approach is also carried forward in the Code and the accompanying technical guidelines (FAO, 1995b).

The FAO technical consultation cited above gives extensive details describing a precautionary approach to fishery management. Several international organizations, including NAFO, are in the process of developing the technical methods for implementing a precautionary approach. Here, I would simply note, as part of my overview of future trends, that the precautionary approach includes the idea of prudent foresight in preventing resource overharvesting and particularly the avoidance of irreversible changes. To do this, it is necessary to identify undesired outcomes, such as reductions in yield below the maximum sustainable yield, or high harvesting mortality on non-target species, in advance to ensure that corrective measures can quickly be applied. The precautionary approach requires all harvesting activities to be under management. Fishing activities should be evaluated to ensure that long-term resource damage does not occur before they are allowed to expand. This latter point is often referred to as appropriately placing the burden of proof for harvesting activities.

Many of the ideas embodied in the precautionary approach and the FAO Code of Conduct (FAO, 1995a) have been included in new US legislation for fisheries management, the Sustainable Fisheries Act of 1996 (NOAA, 1996). The new requirements of the law are that overfishing be addressed for all fisheries resources within the U.S. exclusive economic zone. Stocks must be maintained at or above the level need to produce maximum sustainable yield. Considerations of habitat, by-catch and the timeliness of actions to correct problems are all addressed by the new law.

\section{The New England Groundfish Fishery}

The New England groundfish fishery has been exploited for at least 300 years, but its recent history is of overexploitation, and nearly catastrophic stock declines (Fig. 1). Distant water fleets in the 1960s and 1970s heavily harvested all of the principle groundfish stocks and many other resources of the Georges Bank ecosystem. A detailed scientific description of the ecosystem and its exploitation is given in Backus (1987). Management of the international fishery under the International Commission for the Northwest Atlantic Fisheries (ICNAF, during 1950-79) is described in this symposium volume by Anderson (Anderson, 1998). Suffice it to say that, while the distant water fleets were large and efficient, the US national fleet was of far lower capacity.

With the advent of extended jurisdiction in 1976, management within the US exclusive economic zone became the responsibility of the US Secretary of Commerce. New legislation set up regional fishery management councils to develop management plans for the Secretary's approval and implementation. The New England Fishery Management Council consists of representatives of each of the state governments in New England and members of interested and affected groups from the region. Most of the non-governmental members come from the fishing industry. The Regional Administrator for the US Department of Commerce's National Marine Fisheries Service in the northeast also serves as a voting member of the Council.

The initial plan for managing groundfish in New England after 1976 set quotas for the principle stocks based on the ICNAF quota system. However, these quotas were removed in 1982 because of the complexity 


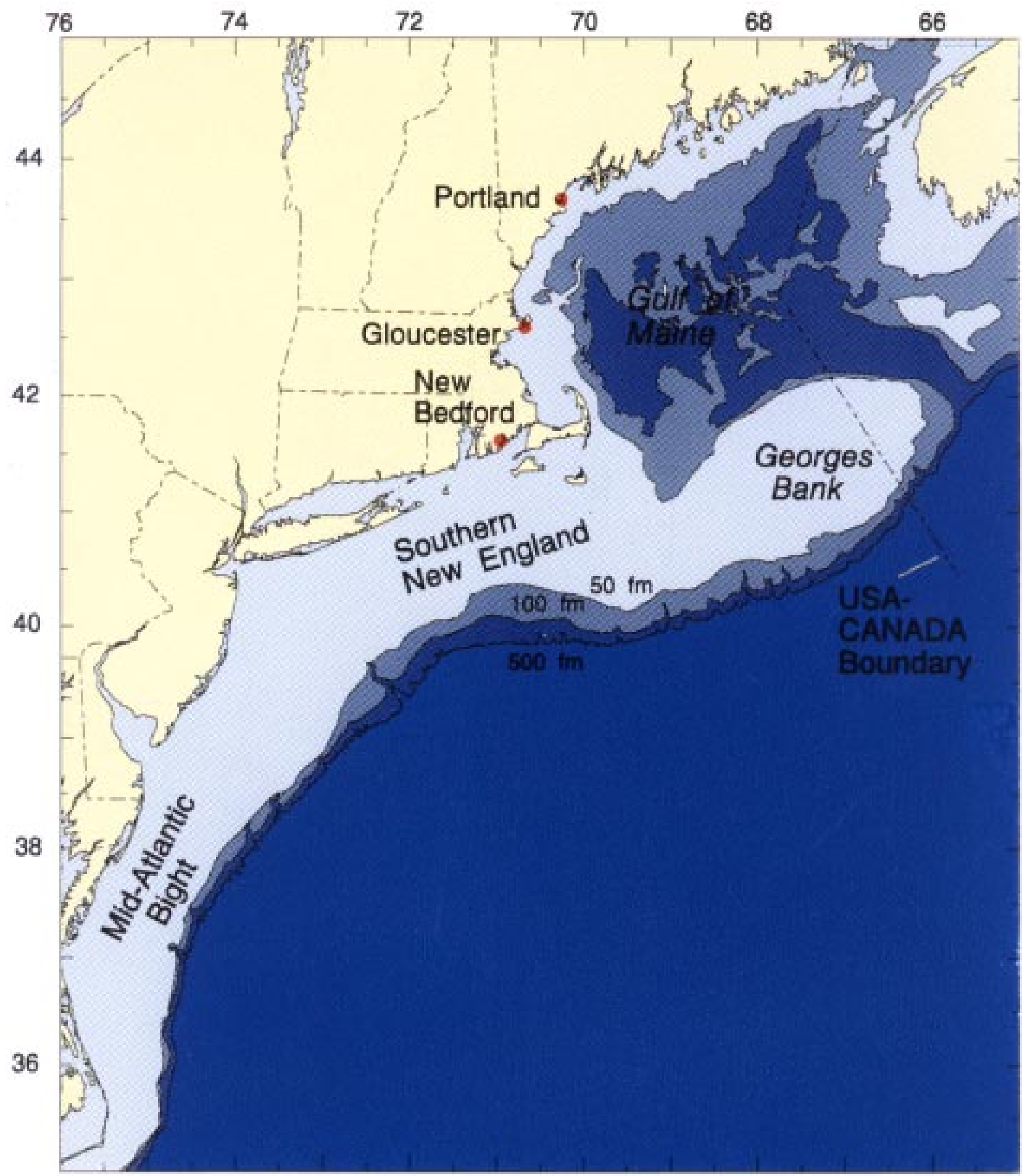

Fig. 1. A) Map of northeastern U.S. fishing grounds, B) U.S. landings of the principle groundfish, cod, haddock and yellowtail flounder. Phases of management are indicated by the vertical lines. See text for details. C) landings and abundance trends for New England groundfish. Landings are from commercial fisheries data, abundance trends are from annual bottom trawl surveys conducted by the National Marine Fisheries Service. 


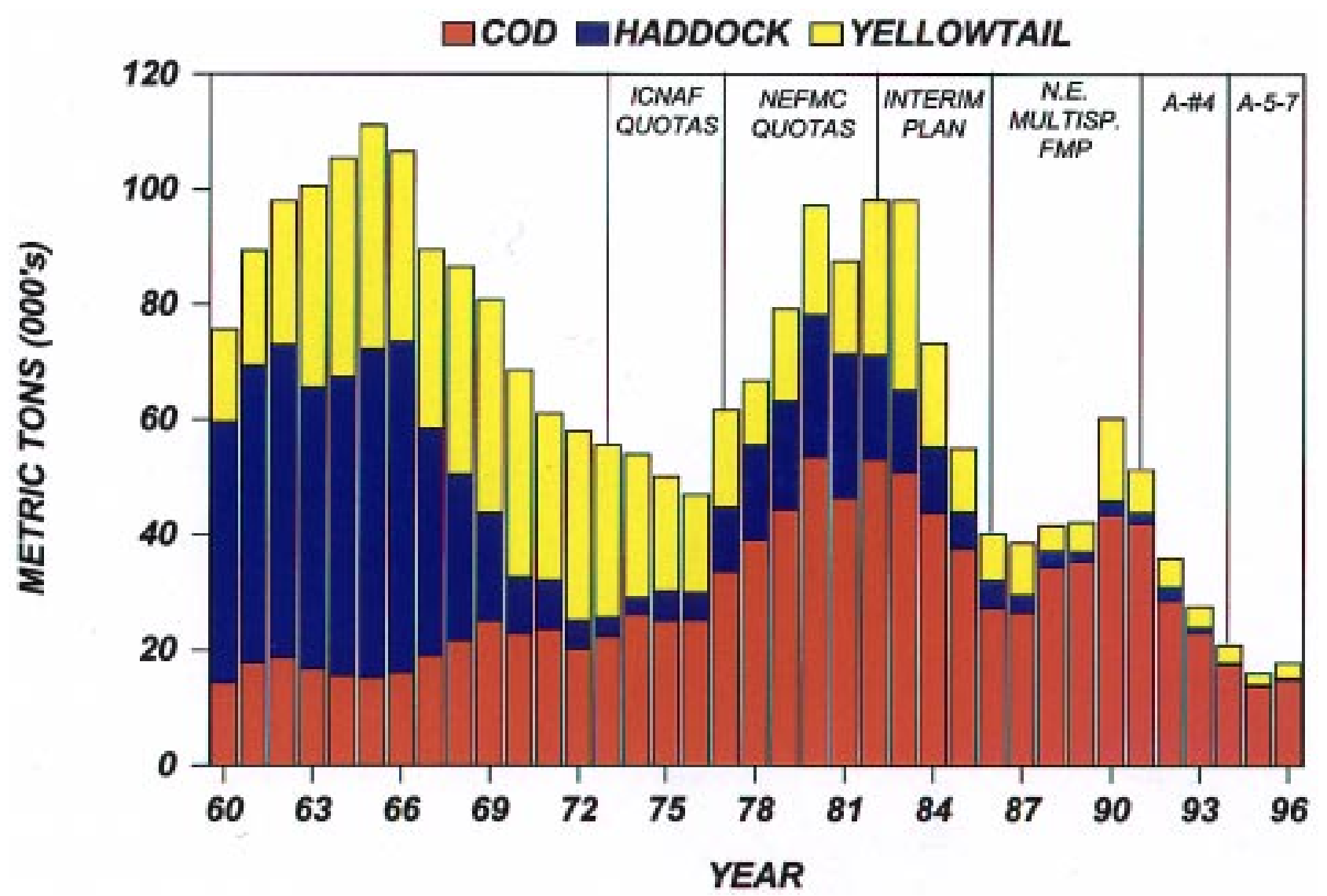

Fig. 1. A) Map of northeastern U.S. fishing grounds, B) U.S. landings of the principle groundfish, cod, haddock and yellowtail flounder. Phases of management are indicated by the vertical lines. See text for details. C) landings and abundance trends for New England groundfish. Landings are from commercial fisheries data, abundance trends are from annual bottom trawl surveys conducted by the National Marine Fisheries Service.

of the system, the difficulty in effectively monitoring and enforcing the quotas and industry opposition to them. In their place, indirect controls such as mesh restrictions were used as the sole management measures under the Northeast Multispecies Fishery Management Plan (NEFMC, 1986) and subsequent amendments 1-4. But US fishing effort and capacity grew rapidly following the departure of the distant water fleets, and the harvesting pressure quickly exceeded the productivity of the stock once again. The scientific advice from the mid-1980s on was that the harvest rate was excessive and severe stock declines were the likely result. This advice proved, unfortunately, very accurate and the principle groundfish stocks declined steadily from the time when the direct control on the harvest was removed. It is a classic case of the pattern Gulland described, with a build-up of overcapacity and accompanying overexploitation.

The failure to come to grips with overfishing kept the principle groundfish resources in a very risky condition in the latter half of the 1980s and early-1990s. Even with mesh size increases, fishing mortality rates were so high the fishery depended almost entirely on newly recruiting age classes. Moderate recruitment from the 1987 year-classes of some of the principal stocks provided an opportunity to reverse the situation, if fishing pressure could be reduced. This good recruitment for several stocks was really the last gasp of the resource. It was not until 1994 that a limited access system and direct control of fishing effort, by regulating days at sea for many participants was implemented. The plan, so-called Amendment 5 , was complex and contained numerous exceptions from access control and days at sea control, but it was the first real attempt to reduce fishing pressure. 


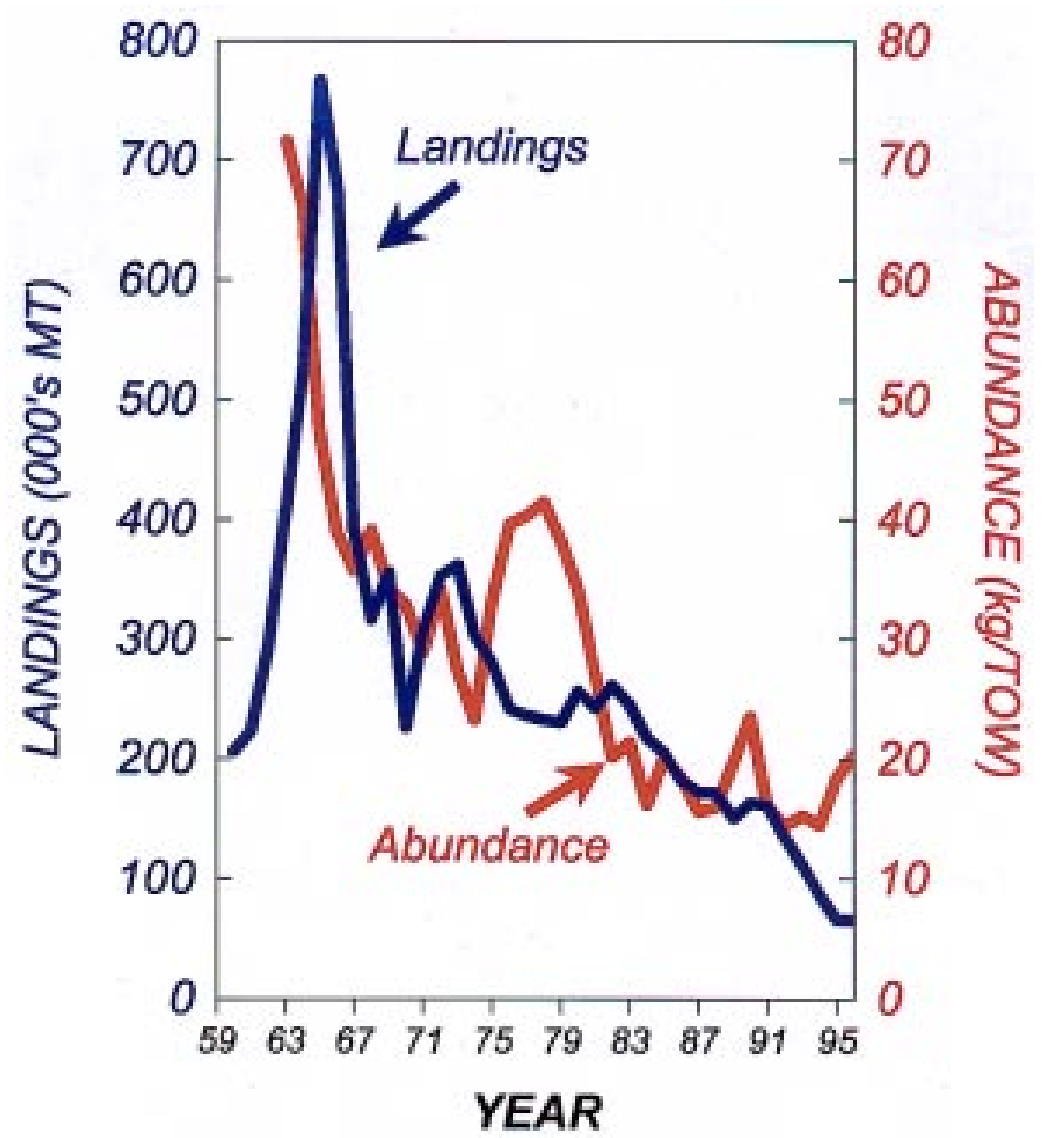

Fig. 1. A) Map of northeastern U.S. fishing grounds, B) U.S. landings of the principle groundfish, cod, haddock and yellowtail flounder. Phases of management are indicated by the vertical lines. See text for details. C) landings and abundance trends for New England groundfish. Landings are from commercial fisheries data, abundance trends are from annual bottom trawl surveys conducted by the National Marine Fisheries Service.

Unfortunately, Amendment 5 was designed to end overfishing, not rebuild depleted stocks. In a sense, it was predicated on the last gasp recruitment of the principle groundfish stocks of cod, haddock and yellowtail flounder. Preserving that recruitment by ending overfishing would have allowed maintenance of the stock at a moderate level, if a strong plan was implemented in 1990 or 1991. But arguments over the development of Amendment 5 took so long, the moderate year-classes were long gone and spawning stock was so low that they were not followed by much of any recruitment compared to historical levels. In other words, Amendment 5 was unable to address the resource conditions that existed when it was finally implemented, that is historically low stock abundance on Georges Bank. The scientific advice a few months after Amendment 5 was implemented recommended that fishing mortality be reduced to as near zero as practicable, rather than the slow reduction planned by Amendment 5. The Management Council began discussing changing the plan to institute recovery.

Four months later, at the request of the Management Council, major closures were instituted by emergency secretarial action on Georges Bank. Almost one third of the bank was closed to fishing and gear restrictions in other areas were implemented. The same strategy of days-at-sea controls along with large closed areas was used, but in a far more restrictively plan, Amendment 7 (note: Amendment 6 instituted a low trip limit on the collapsed Georges Bank haddock by secretarial action, over the opposition of the Council) implemented in July of 1996. 
The result, according to the 1997 stock assessments, is somewhat startling (Fig. 2; SAW, 1997). Fishing mortality rates on cod, haddock and yellowtail flounder on Georges Bank are at or below the $\mathrm{F}_{0.1}$ for the first time since before the arrival of distant water fleets in the 1960s. The combination of effort control and area closures had set the conditions for stock recovery, though biomass had only increased marginally for most species. The prognosis, if the fishing pressure can be kept low, is for a dramatic increase in biomass over the next 5-10 years. The challenge is to keep fishing mortality low as the biomass increases, to set the stage for a sustainable fishery with relatively high yield.

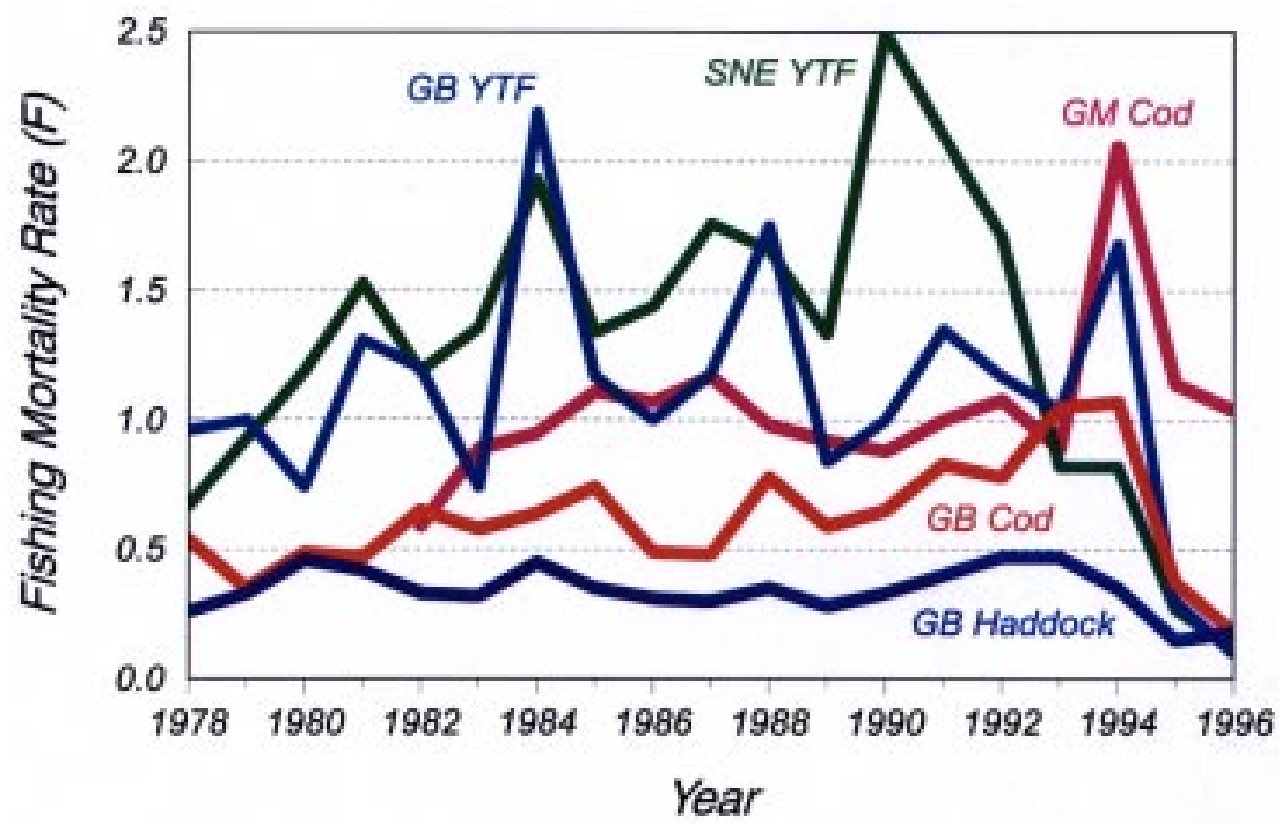

Fig. 2. Time trends in fishing mortality rates for principle groundfish stocks in New England. GB YTF is Georges Bank Yellowtail flounder, SNE YTF is southern New England yellowtail flounder, GM Cod is Gulf of Maine cod, GB Cod is Georges Bank cod, and GB Haddock is Georges Bank haddock.

\section{Lessons and Predictions}

The simple message from this example is that controlling fishing pressure is certainly possible, but more importantly, is a pre-requisite for recovery of depleted stocks. Furthermore, if management was able to be more responsive to the scientific advice in controlling fishing, depletion may be avoided in the first place. For the purposes of this paper, however, there are other, more subtle observations of changes in fishery management that I have observed during the course of the development of this stock recovery plan.

There has been a fairly dramatic diversification of the industry both in terms of methods and products brought to market (Fig. 3). While market development has always been important, the very low abundance of traditional species and the severity of the necessary restrictions on groundfishing in New England has given greater impetus to the need to sell whatever can be caught and to keep quality and therefore price high.

The New England groundfish limited access program consists of only a rudimentary moratorium on new entrants, and it is not particularly restrictive on participation. However, there has been some initiative to reduce long-term capacity through vessel buyouts and short term capacity reduction through busi- 


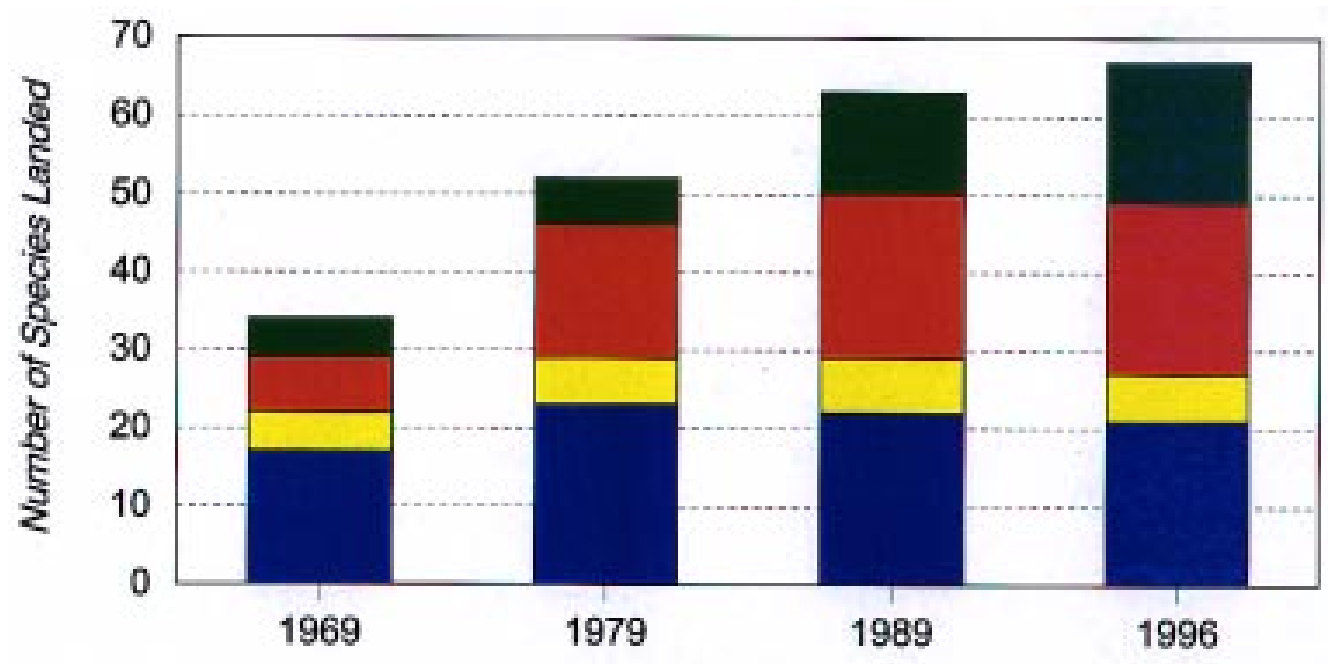

\section{Groundfish $\square$ Pelagics $\square$ Other Fish $\square$ Invertebrates}

Fig. 3. Number of species landed in three major New England ports in four decades.

ness failures has also occurred (short term, because these permits could be re-activated in future under the present rules). The sentiment to maintain a strong owner/operator component of the industry is still dominant in New England, even with the difficulties of the last few years. So, while there is little question in my mind that capacity needs to be reduced, there is also little question that it will remain an industry primarily comprised of small businesses, and the route to capacity reduction is unclear.

In an open access setting, with indirect controls on fishing and a relatively inflexible management system, there is little incentive for self-policing of the management regulations. In other words, there may be a higher level of tolerance within the industry for violators of the rules. Moving toward a more restrictive management system, which adjusts with regular updates on resource status, that allocates fishing privileges to the fleet (days at sea allocations for example) based on that status presents a different picture however. In this circumstance, someone violating the rules more directly impacts on the ability of all the other industry participants to fish. Simply put, if the harvest rates go up, the days at sea for each boat go down. The end result over time will be a very low tolerance for violators.

Finally, the New England groundfish management plan is enormously complicated, with many exceptions, special provisions and rules to micro-manage vessel operations. Contrary to conventional wisdom (often, and in this case, wrong), these complications are not the result of bureaucratic meddling or government over-regulation, but due to efforts to accommodate special needs of various parts of the industry. So, in order to allow a few vessels to continue operating in a particular fashion, exceptions are written into the rules, and then some complicating offset is needed to keep the program intact. The end result is a complex management plan for managers and industry. The tolerance for such complicated rules will also decrease over time, in the same way as for violators. The consequence is not simpler rules that the industry prefers, but simpler rules that remove exceptions, and are more workable. As with tolerance for violators, this is likely to be a long process.

\section{Future Precautionary Management}

To conclude, I would like to reflect back on the main ideas of the precautionary approach to fishery management and relate them to the groundfish example and my predictions for the future. No one could argue that prudent foresight was used in the history of the management of New England groundfish, except 
that the scientific advice warning against undesired outcomes was clear long in advance of an effective management program. However, the current management structure at least allows such foresight to be brought into play and the management plan clearly identifies undesirable outcomes. Further, the changes are probably not irreversible, neither in fishing effort nor resource status, if the early evidence holds true.

In order to be precautionary in future, a key missing component is needed. It is essential to have prior identification and agreement on the management actions to be taken in response to changing resource conditions. This is a high hurdle for fishery managers. It requires developing a plan that reduces the amount of discretion that will be exercised for each controversial management decision, because there would be prior agreement on a course of action. Developing a management strategy in advance may reduce the influence of short-term political factors in making a decision on how to respond to changing conditions. This may be a good thing for the fish, but a difficult step in a political world. We are not there now, but we may get to this point in 50 years.

I think if all of my predictions come true, it will be possible to be precautionary, and therefore not repeat the groundfish example. These changes will not be easy, but are possible.

\section{Acknowledgments}

I thank Emory Anderson and Hans Lassen for suggesting I prepare this paper and Patricia Kurkul for her helpful comments on the manuscript.

\section{References}

ANDERSON, E. D. 1997. The history of fisheries management and scientific advice - the ICNAF/NAFO history from the end of World War II to the present. J. Northw. Atl. Fish. Sci., 23: 75-94 (this volume).

BACKUS, R. 1987. Georges Bank. MIT Press, Cambridge.

BROMLEY, D. W. 1992. The commons, common property and environmental policy. Envir. Res Econ., 2: 1-17.

FAO. 1995a. Code of conduct for responsible fisheries. Fisheries and Agricultural Organization of the United Nations, Rome, 41 p.

1995b. Precautionary approach to fisheries Part 1: guidelines on the precautionary approach to capture fisheries and species introductions. FAO Tech. Pap., 350: $52 \mathrm{p}$.

NEFMC. 1986. Northeast multispecies fishery management plan. New England Fishery Management Council, 361 p. NOAA. 1996. Magnuson-Stevens Fishery Conservation and Management Act: as amended through 11 October 1996. NOAA Tech. Memo., NMFS-F/SPO-23, $121 \mathrm{p}$.

ROSEnBERG, A. A., M. J. FOGARTY, M P. SISSENWINE, J. R. BEDDINGTON, and J. G. SHEPHERD. 1993. Achieving sustainable use of renewable resources. Science, 262: 828-829.

SAW. 1997. Report of the 24rd Northeast Regional Stock Assessment Workshop: advisory report on stock status. National Marine Fisheries Service, Woods Hole, MA., 47 p.

SISSENWINE, M. P., and A. A. ROSENBERG. 1993. Marine fisheries at a critical juncture. Fisheries, 18(10): 6-14. UN. 1995. Agreement for the implementation of the provisions of the United Nations Convention on the Law of the Sea of 10 December 1982 relating to the conservation and management of staddling fish stocks and highly migratory fish stocks. UN Conference on Straddling and Highly Migratory Fish Stocks Sixth Session A/Conf. 164/37, 8 Sep 95. 
